\title{
Upper Limb Bionic Orthoses: General Overview and Forecasting Changes
}

\author{
Gustaw Rzyman ${ }^{\circledR}$, Jacek Szkopek ${ }^{\circledR}$, Grzegorz Redlarski *(D) and Aleksander Palkowski
}

Faculty of Electrical and Control Engineering, Gdansk University of Technology, 80-233 Gdansk, Poland; gustaw.rzyman@pg.edu.pl (G.R.); jacek.szkopek@pg.edu.pl (J.S.); aleksander.palkowski@gmail.com (A.P.)

* Correspondence: grzegorz.redlarski@pg.edu.pl

Received: 9 July 2020; Accepted: 24 July 2020; Published: 31 July 2020

\begin{abstract}
Using robotics in modern medicine is slowly becoming a common practice. However, there are still important life science fields which are currently devoid of such advanced technology. A noteworthy example of a life sciences field which would benefit from process automation and advanced robotic technology is rehabilitation of the upper limb with the use of an orthosis. Here, we present the state-of-the-art and prospects for development of mechanical design, actuator technology, control systems, sensor systems, and machine learning methods in rehabilitation engineering. Moreover, current technical solutions, as well as forecasts on improvement, for exoskeletons are presented and reviewed. The overview presented might be the cornerstone for future research on advanced rehabilitation engineering technology, such as an upper limb bionic orthosis.
\end{abstract}

Keywords: biomechanics; exoskeleton; rehabilitation; robot-assisted therapy

\section{Introduction}

The current state-of-the-art in bionic orthoses has its beginning in classical antiquity. The first known works related to this topic were created by Archytas from Tarentum in 350 BC. He invented several mechanical devices, such as a flying bird powered by steam [1]. His works gave rise to modern robotics. In the Middle Ages it was common to construct devices, which now can be named androids, for entertainment. They were given roles to welcome guests at the entrance, play instruments, open the door, or do other simple activities. To power the androids, former constructors used gravity, energy stored in a spring, or flowing water. The word "robot" - describing a mechanical machine-was used for the first time in the science fiction play "Rossumovi Univerzální Roboti" by Czech writer Karel Čapek in 1920 [2-4]. The following decades brought dynamic development in robotics due to intense research and numerous projects being worked on all over the world-simple robots have been expanded to currently used, sophisticated and complex devices.

An example of a medical device which design shares similarities with robotic devices is an orthosis. The word orthosis comes from Greek "ortho" and means "to straighten" [5], thus the purpose of the orthosis is to stabilise joints and groups of muscles that have suffered an injury. The creator of the first known orthosis was French surgeon Ambroise Paré in the middle of XVI century [6] whose metallic brace was introduced for correction of scoliosis. Although it did not exploit any movement, since then, orthosis devices have been constantly improved. US military efforts in increasing endurance and force of human muscles have led to the idea of a bionic orthosis.

The first attempt to construct human muscles amplifier was made by General Electric company in 1965 [7]. The project was called Hardiman (Figure 1a) and was expected to increase human lifting capability up to $650 \mathrm{~kg}$. Unfortunately, it generated a raising force of only $340 \mathrm{~kg}$ and the orthosis was enormous. After several attempts of improving, the Hardiman project was abandoned. In subsequent 
decades many constructors tried to overcome limitations of contemporary materials. Finally, in the early 1990s, the technology was sufficiently advanced to build a compact version of Hardiman. One of the first patented exoskeletons was the "Three axis mechanical joint for a power assist device" created in 1994 [8]. Its main objective was to amplify a human muscle force.

While assistive devices for primarily healthy soldiers were developed, it was 1970 when robotic solutions finally found way to be applicated in a health purpose. That year an orthopedic surgeon from Toronto, Robert B. Salter, investigated regeneration and healing possibilities of articular tissues coming from continous passive motion (CPM) observed on rabbits. This research was the key which promoted healing joint cartilage by appropriate motor treatment [9].

Now, we observe more tries to implement the idea of exoskeletons in biomedical engineering, especially in engineering of rehabilitation systems [10-15]. We can divide bionic orthoses into two groups: the first group is intended to restore muscles to their original efficiency (Figure 1b), while the second (Figure 1c) is supposed to improve daily life of people having paresis [16].

The purpose of this article is to review the latest technology used in constructing a bionic orthosis meant for rehabilitation, as well as to indicate the direction of its future development. As a bionic orthosis we mean a rehabilitation device which, by means of dedicated software, automatically determines the state of the rehabilitation process and, if necessary, supports it. The element "bionic" suggests using biological factors for purpose of control strategy. It must be noted that this article will not deal with the question of neurological aspects, because of its complex nature, which is described more fully by Gassert et al. [17] . Smart orthoses are the future of modern medicine and it is reasonable to claim that using bionic orthoses in rehabilitation of the upper limb may be more effective than currently used methods [10,18-27].

The literature review was made with the help of "Scopus", "Google Scholar", "IEEE Xplore" and "Research Gate". The general search phrases were a combination of words: "rehabilitation", "robot", "exoskeleton", "upper limb", "orthosis".
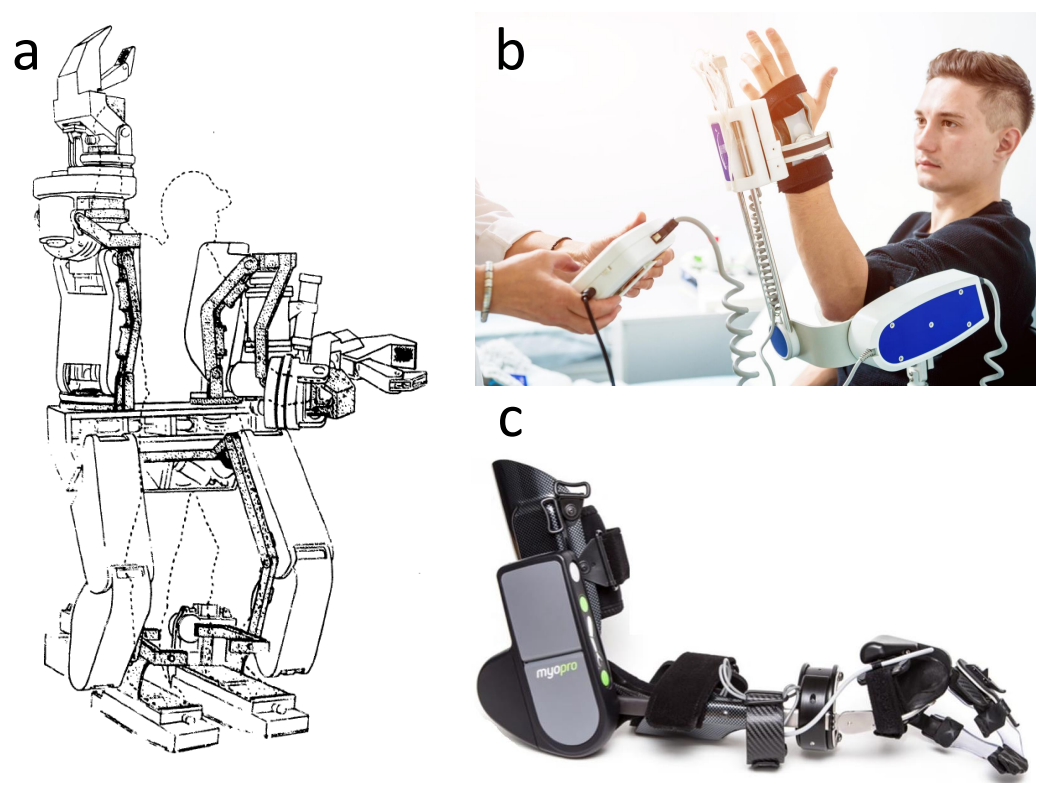

Figure 1. Examples of bionic orthosis solutions: (a) Hardiman (figure by Bruce Fick and John Makinson), (b) Myopro (reproduced with permission from [28], Myomo, 2020), (c) Patient on continuous passive range of motion machine (figure from [29]).

\section{Medical Device Regulations}

One of the most important aspects of constructing biomedical devices are ethics and law restrictions. Referring to human rights, especially to right to health, it is neccesary to guarantee a highest quality health care service, which by definition cannot make ones condition worse. Thus, 
all of the products intended for sale are nowadays covered by specific directives and regulations provided by countries and organisations. The most recognized is Chartered Engineers Certificate or simply CE introduced by European Union for economic purposes. Individual regulation units that take significant part in global trade include the Food and Drug Administration (FDA) in the USA and Pharmaceuticals and Medical Devices Agency (PMDA) in Japan [30,31]. With reference to smaller entities, their regulations law commonly rely on one of the mentioned above in order to facilitate movement of products. For example, a medical device directive of ASEAN (Association of South-East Asian Nations) refigures European standards and some of the FDA's methods [32].

The common property of all of the regulations is fact they are based on risk assesment [33,34]. The result of such a procedure is assigment of proposed device to one of the risk classes, where 1st is with lowest risk and the last one level (in all cited is equal 4) is highest. This classification affects further steps in certification procedure, e.g., restrictions, and that is why some standarisation work is carried out between the greatest units [35].

Focusing on authors regional law, i.e., Poland and European Union, a main applicable directive is Medical Device Directive (MDD) 93/42/EEC, which is compatible with ISO 13485. In this case a bionic orthosis will be classified in class $\mathrm{Ilb}$, as an active therapeutic device that exchanges energy to the human body in potentially hazardous way [36]. The main difference betwen classes is that a compliance with directive of class I could be examined and declared by producer while classes $\mathrm{IIa}$ IIb and III require qualified institutions verification. As to the requirements, they are a set of general principles that must be fulfilled in process of the CE certification. Referring to some of them, a device must be designed to avoid the risk of electric shocks during both normal and single fault condition. Moreover, alarm systems must be provided in case of any power failure. Those describing mechanical construction require usage of biocompatible materials and protection against mechanical risks resulting from, e.g., moving parts. Same general restrictions are found in the FDA's list and are expanded by non-clinical performance testing. In opposition, the FDA has a database e-CFR where already certificated devices are placed with appropriate information, such as class of risk and requirements-information cited above is taken from paragraph 890.3480 "Powered lower extremity exoskeleton" (upper is not available) [37].

Instead of compliance with Machine Directive 2006/42/WE and therefore Electrical 73/23/ewg, which are additionaly required in EU members law, appropriate ISO standards should be respected due to two things. First of all, they give precise information about parameters and it values and secondly EU directives are based on ISO standards [38-40]. It should be mentioned that problems such as mechanical resistance could be simply solved by 3D modeling software.

Requirements concerning on relevant staff and patient training, and providing real time information about the state of patient and device could be omitted, due to modern multimedia systems which will be described later in this article.

The most problematic aspect seems to be a clinical trial. In order to be authorised for such tests it requires approval not only from regulatory authorities but also research ethics committee. The overall process of an evaluation is based on a comparison between possible forces produced by device and acceptable loads of human body which are known from biomechanical research. The problem occurs when these parameters became individual, i.e., are not known or may vary in time, e.g., people with osteogenesis imperfections. This situation may in most cases lead to rejection of the application, which is completely understandable. However, this raises the question what new procedures should be taken into account, how new rehabilitation devices should be designed and which parameteres require detailed research to allow patients with these particular cases to the newest technology.

In conclusion, the lack of clarity in the current legislation is caused by dynamically developing technology. For this reason, existing directives and regulations for medical devices are too general to give a clear view on all of the robotic aspects. The natural course is adaptation of these procedures to systematically improve solutions, and the best evidence of this has been the recently released IEC standard 80601-2 for medical electrical equipment, especially part 78 "Particular requirements for basic 
safety and essential performance of medical robots for rehabilitation, assessment, compensation or alleviation" [41]. This will hasten an implementation of the bionic orthosis and will popularize them, which in effect will result with extended experience. Thus all of the patients will be given a chance to use modern technologies.

\section{Mechanical Construction}

Progenitors of the modern bionic orthosis were used to improve human muscle force. They had a simple and non-autonomous control system, while the majority of current robotic technology use brain-computer interfaces [42-48]. Primitive exoskeletons were unnecessarily heavy, with their weight reaching over $700 \mathrm{~kg}$ [49]. It was caused by the weight of materials and drives used in their first prototypes. The basic construction material used to build bionic orthoses in the middle of the 20th century was steel (with breaking tensile stress-to-density ratio of 75), which was because of its strength properties [50]. For the same reason, in combination with old type massive actuators, these devices had enormous sizes. Therefore considerations of mobile solutions had to be abandoned [7].

In the last applications we can distinguish several types of motion assistance: active devices, passive device, haptic device, coaching device, active exercise and passive exercise [51]. The first construction is recently one of the most developed due to its multipurpose, light weight and price competitive potential [52]. The main features of mechanical design of such orthosis are the actuating and transmission system as well as applied materials (Figure 2). Same as in prosthetics, weight, mobility and comfort play a significant role $[53,54]$. However, prosthetic devices offer an additional inner space which allows placing actuators and transmission mechanisms in device contours [55-57]. Thus, the choice of the actuating unit may affect the entire apparatus.

Most frequently, the elbow joint is the one which is driven directly with a motor installed on lateral side of the arm. This solution, as well as rigid transmission (e.g., n-bar linkage, gear) requires a special attention to compatibility of joint rotation axes and bionic orthosis axes. Currently, several types of mechanisms are used for this purpose, including: direct matching of joint centres, linkage for remote centre of rotation, redundant linkage structure, and serial linkage attached to distal segment [58]. Incorrect matching of rotation axes can lead to exoskeleton damage or limb injury $[15,59,60]$.

In opposition to these solutions that are very bulky or actuators cannot be placed directly in joint axis $[61,62]$. It is possible to use flexible transmission. The best example of such appliance is a tendon driven system. In the simplest way, appropriate parts of the body are connected to motors via a Bowden cable, thus making them mostly unnoticeable and providing frictionless movement $[63,64]$. On the other hand, the mechanism imposes an antagonistic control thereby redoubles the number of actuators. It is possible to avoid this phenomenon with pulley mechanism application, but simultaneously, as with rigid solutions, construction gets more complex and enlarged $[65,66]$. Moreover, underactuation must be taken into account.

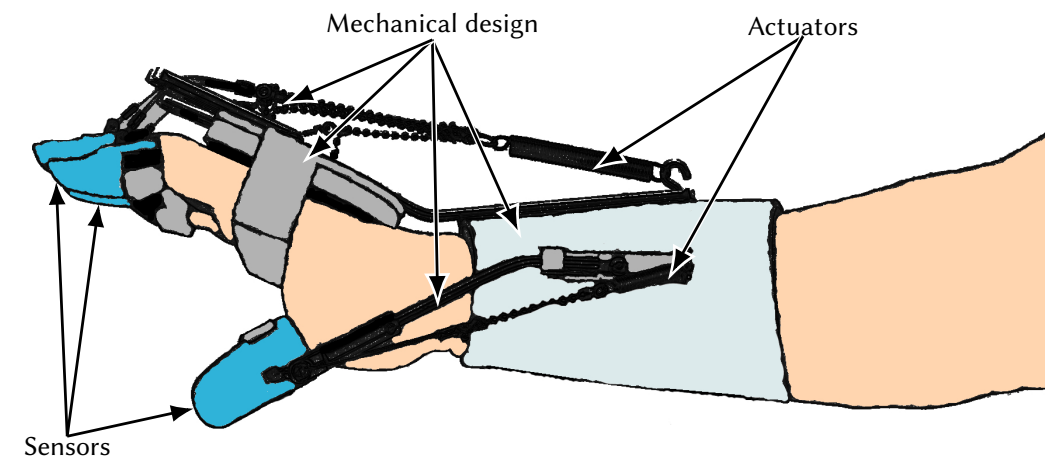

Figure 2. Components of a bionic orthosis - adapted with permission from Saebo, 2020 [67].

Aspirations to build lighter active orthosis, which would be useful in everyday life turned engineers' attention, in the aspect of applied materials, to alloys. Similar strength properties, 
significantly lower weight, and higher breaking tensile stress-to-density ratio (162) than steel were the reason why aluminium is often used in modern bionic orthoses [68,69]. In general, materials used to create an exoskeleton are: bakelite, surgical stainless steel, aluminium alloys (copper, magnesium, or manganese), acrylonitrile butadiene styrene (ABS), polylactide (PLA), or shape memory alloys (SMA) $[44,68,70-75]$. A compilation and comparison of properties of the aforementioned materials can be found in Table 1.

Table 1. Properties of materials used in the production of bionic orthoses.

\begin{tabular}{|c|c|c|c|c|c|c|}
\hline & Tensile Strength (MPa) & Yield Strength (MPa) & Density $\left(\mathrm{kg} / \mathrm{m}^{3}\right)$ & Processing Difficulty & Price (USD/kg) * & References \\
\hline Stainless steel & $500-700$ & 200 & 8000 & Medium & 25 & [50] \\
\hline Aluminium alloy & $510-540$ & $430-480$ & 2810 & Difficult & 15 & {$[68,69]$} \\
\hline PLA & 800 & $70-100$ & $900-1500$ & Easy & 2 & {$[72,73]$} \\
\hline SMA & 1000 & 200 & 6500 & Difficult & 100 & {$[70,71,76]$} \\
\hline Carbon fibre & $2800-5000$ & 840 & $1600-2000$ & Very difficult & 25 & [75] \\
\hline
\end{tabular}

It is also common to produce some parts using carbon fibre to make the orthosis lighter and more durable. Only a couple of years ago there were no rehabilitation devices fully manufactured of carbon fibre because of its poor ability to resist transverse loads [77]. However, in recent years, a bidirectional carbon fibre was created, which is characterised by a higher ability to resist transverse loads and a high breaking tensile stress-to-density ratio (2167) [75].

Formerly, a number of other materials were used [44], but because of their inadequate characteristics they have been replaced by modern metal alloys and plastics. Present bionic orthoses are made of different materials depending on their purpose. Lower limb or pelvic orthoses are exposed to higher stresses compared to the orthoses of the upper limbs, therefore, metal alloys and carbon fibres are usually used due to their strength properties. Orthoses of the upper limbs are not subjected to high stress or force and, consequently, materials used in their production are lighter and their machining process is easier. For this reason, it was natural to use 3D-printed PLA and ABS in orthosis manufacture process [78-83]. An additional advantage of using a 3D printer is low production cost, which can be lower than 35 USD for the entire construction-as with the prosthetics made at the Jacobi Medical Center in New York [84].

\section{Actuators Overview}

Most frequently encountered upper limb hardware systems are based on electric, hydraulic and pneumatic actuation [85-90]. In the past, primitive hydraulic drives were used in exoskeletons, as it was the only type of drive that could set in motion a heavy steel frame. The aforementioned Hardiman project was composed of a complex hydraulic and electronic network. With the technology development and new materials, engineers started to adapt, first of all, new lightweight motor based drives. Moreover, the number of smart materials used as an actuator in bionic orthoses is rising increasingly. In this type of materials we can observe change of physical properties or shape under the influence of, e.g., an electric, magnetic and temperature field [71,91]. An exemplary classification of described and others actuators is shown below (Figure 3).

Easily accessible, cheap and with wide range of power and size DC motors are the most common types of drives. Compared to others, they are distinguished by extensive experience and knowledge in control methods and that is why they are used in limb exoskeletons [92-94] and in stationary rehabilitation robots [95-98].These electric actuators can be divided into two basic groups: brushed and brushless.

Brushless motors (BLDC) have much higher torque and are more compact than brushed (Table 2), what is frequently used in elbow direct actuation $[15,99]$, but that is not a rule and brushed motors also appear [87]. On the other hand, they require a dedicated control board to correctly change polarisation and so regulate speed/torque. 


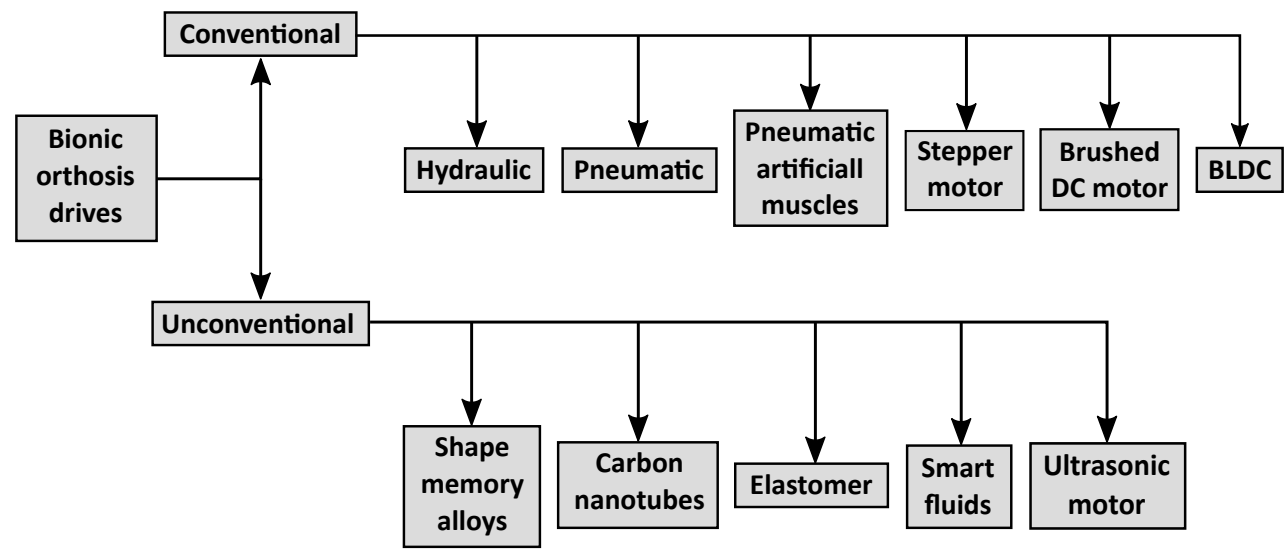

Figure 3. Types of bionic orthosis drives.

Brushed motors could be simply controlled by changing the voltage level, which makes them easy applicable; however, brushes wear over time, which shortens their lifetime. They are a base for other types of actuators such as servomotors or linear actuators-devices which consist of an integrated gearbox and feedback circuit and allows for precise displacement control, speed, and acceleration of the motor shaft $[66,100]$. It should be noted that both brushed and BLDC motors require an additional gearbox to generate appropriate power and speed [59,65]

Currently, the stepper motor is one of the simplest types of drive to control. Unfortunately, these motors have many serious disadvantages, such as discontinuous work (jumping), large dimensions (at high torque values), high energy demand, and high heat output during operation.

In reference to the next group, pneumatic and hydraulic actuators, there are no applications using this type of drive due to oversized end-effectors and additional equipment (valves, regulators, gas tank and a compressor) which results in the relatively large and bulky system. A particular type of such actuators is the McKibben muscle modelled after the human muscle. A pneumatic muscle, used in several research exoskeleton projects [101,102], is a first applied and developed drive considered as a artificial muscle, because of a human muscle properties such as light weight and elasticity $[103,104]$. Nevertheless, it still possesses imperfections of pressurized medium actuators, more precisely, equipment requirements.

Table 2. Characteristics of conventional bionic orthosis drives.

\begin{tabular}{lccccc}
\hline & $\begin{array}{c}\text { Power Density } \\
(\mathbf{W} / \mathbf{k g})\end{array}$ & Torque (Nm) & $\begin{array}{c}\text { Dimensions } \\
(\mathbf{m m})\end{array}$ & Weight (g) & References \\
\hline $\begin{array}{l}\text { Micro Servos } \\
\begin{array}{l}\text { Expert } \\
\text { Electronics SL260 }\end{array}\end{array}$ & 110 & 0.109 & $21.6 \times 11.2 \times 19.1$ & 9.1 & {$[105]$} \\
$\begin{array}{l}\text { Coreless motor } \\
\text { MicroMo }\end{array}$ & 675 & 0.728 & $\varnothing 22 \times 51.3$ & 6 & {$[105]$} \\
$\begin{array}{l}\text { 2224-012SR } \\
\text { Artificial muscle }\end{array}$ & 46 & & & & [106] \\
$\begin{array}{l}\text { Festo } \\
\text { Brushless motor } \\
\text { Maxon Motors }\end{array}$ & 125 & - & $260 \times 30 \times 30$ & 136 & {$[107]$} \\
$\begin{array}{l}\text { Pololu Micro } \\
\text { Metal Gearmotor }\end{array}$ & 914 & 9.8 & $60 \times 59 \times 56$ & 80 & [108] \\
$\begin{array}{l}\text { Pololu Micro } \\
\text { Metal Gearmotor }\end{array}$ & 136 & 0.89 & $10 \times 12 \times 29.5$ & 10.5 & [108] \\
\hline
\end{tabular}

Recently, a growing interest to unconventional solutions is observed (Figure 4). The new generation of actuators, based on phase transformation materials and activated by different stimuli, is constantly developed in order to obtain units that are more efficient and have smaller dimensions. 
These will definitely revolutionize robotics, including orthotics; however, most of them are in early design stages.

The most popular materials, which use a change in crystal lattice as the source of movement, are shape memory materials (SMA). They are activated with a temperature field, e.g., when SMA is formed to shape under an external load (martensite) and when it is heated, it will recover to original shape (austenite). Such a working principle offers silent work, small weight, high power density, long lifetime (Table 3 ) and the possibility to program a shape of the material, where it is commonly used in shape of a thin wire or a spring [54]. Nevertheless, shape memory alloys exhibit some serious problems, where relatively slow work and high bandwidth, associated with low thermal conductivity, are the main ones $[71,109]$. Whilst it may be used for a slow movement rehabilitation, a high hysteresis makes it difficult to control.

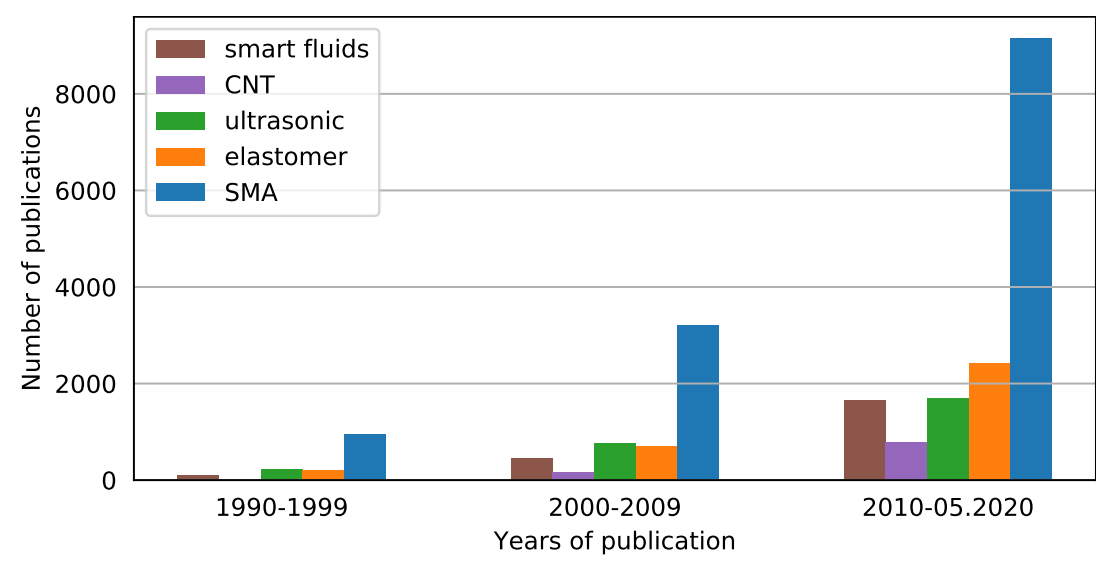

Figure 4. Publications on unconventional actuators.

Polymeric plastics and natural elastomers with elastic deformation capabilities are also used as materials for bionic orthoses drives. These materials increase the performance of conventional drives, such as pneumatic and hydraulic drives [110]. Polymers of this type possess high electrostatic features (material elongation in one direction under the applied voltage) [71]. There are also dielectric elastomers, which change their shape in two directions upon applied voltage [111]. A feature that currently disqualifies this solution is high voltage, expressed in $\mathrm{kV}$, required to activate actuator $[45,112,113]$.

Another material for smart actuators is carbon nanotubes (CNT). The CNT find their application in many areas of technology and medicine [114]. In bionic orthoses, their use was proposed in the early 2000s as material for artificial muscles [71]. However, satisfactory parameters of CNT actuators were recorded only in the tests published by Gendron et al. in 2016. The study created carbon nanotube polymer actuators containing metal chalcogenides: boron nitride $(B N)$, tungsten disulphide $\left(W S_{2}\right)$, and molybdenum disulphide $\left(M o S_{2}\right)$. These supplements have a positive effect on elasticity, and increased strain and blocking force. CNT have good strength properties, especially the tensile strength is extremely impressive.

Intelligent fluids are also used in the production of bionic orthosis drives. Unluhisarcikli et al. [115] used electrotherapeutic fluid as an actuator in an upper limb rehabilitation robot. This material changes its dynamic viscosity under the influence of an electric field. Magnetorheological fluid (MRF) is a substance composed of ferromagnetic particles, which change their dynamic viscosity under the influence of a magnetic field. This substance was expected to improve drive operation in a hand exoskeleton [116]; however, they can be only applied in stationary devices due to required additional equipment, the same as in pneumatic/hydraulic case.

There are many other drive technologies that may be used in bionic orthosis, but for many reasons they are not able to be applied yet or were already tested and resulted in some objections. For example, an ultrasonic motor, characterised by high torque at low speed, was examined by WOTAS researchers who found a problem with tracking slow voluntary movements [117]. Another example, piezoelectrics, 
although simple structures with low rates of energy demand and precise operation, exhibit a very low force capability [118]. Same with ionic polymers, which, in opposition to the aforementioned examples, the main disadvantages of are the liquid environment of the actuator [112,119].

Taking into account above comparison of both conventional and unconventional actuators, a DC motor is, for this time, the best choice as a driving unit because of its low price, many control methods and universality (wide range of parameters, servomotors, linear actuators). However, in reference to the statistic from Figure 4, all the research progress of artificial muscles should be followed as it will dominate the actuators market, primarily affecting lightweight devices with high mobility levels, such as bionic orthoses.

Table 3. Characteristics of unconventional bionic orthosis drives.

\begin{tabular}{lccccc}
\hline & $\begin{array}{c}\text { Power Density } \\
\text { (W/kg) }\end{array}$ & $\begin{array}{c}\text { Average } \\
\text { Efficiency (\%) }\end{array}$ & Density (kg/m $\mathbf{m}^{\mathbf{3}}$ ) & $\begin{array}{c}\text { Product Life } \\
\text { Cycle (Number } \\
\text { of Cycles) }\end{array}$ & References \\
\hline SMA & $1000-50,000$ & $<5$ & 6450 & $10^{7}$ & {$[71,109]$} \\
CNT & $10-270$ & $>22$ & 1000 & $\begin{array}{c}140,00033 \% \\
\text { reduction }\end{array}$ & {$[71,114,120,121]$} \\
Elastomer & $500-5000$ & 25 & 1000 & $10^{7}$ & {$[71,110,111]$} \\
MRF & 690 & NDA & 3000 & NDA * & {$[116]$} \\
Ultrasonic motor & 36 & $18-80$ & 1620 & NDA * & {$[117,122]$} \\
\hline
\end{tabular}

* No data available.

\section{Sensory System}

Sensors corresponding to human senses are a necessary equipment for a bionic orthosis as both play control and safety functions. They allow the patient and physiotherapist to determine forces, which are essential for proper functioning of the orthosis/exoskeleton system and providing protection against injury. Exoskeletons share the same transducer technologies as other robotics.

We can designate several popular sensor technologies: touch sensors, encoders, force/torque sensors, relative position sensors, absolute position sensors and distance sensors. Moreover, different sets of cameras are used more often for distance measurement or shape recognition and interpretation. Lee et al. [123] divided sensors into two basic groups: position-movement and force-pressure sensors. The first group includes: encoders, linear variable differential transformers, potentiometers, accelerators, inclinometers, magnetic sensors, electro-goniometers, and MEMS Inertial Sensor Devices. The second group includes: strain gauges, force/torque sensors, pressure sensors, piezoelectric sensors, piezoresistive polymers, and capacitive force sensors. A basic comparison of tranducer technologies used in orthoses is presented in Table 4.

First of all, limit switches should be installed in all moving parts of a bionic orthosis, which cut off power supply to the orthosis in an emergency situation (e.g., when the inclination limit is exceeded). These sensors are passive type-they do not affect the control (no feedback) and operate only in two positions (on or off), without intermediate states. The electrical limit switches have a very short response time, which makes them ideal for protection against undesirable inclination of a bionic orthosis. They also support first level safety mechanism—-passive mechanical end stops [124].

The Hall effect sensor was used by Wege et al. to measure inclination angles of individual parts of an orthosis [125]. Scientists used also a force sensor acting in three planes with the accuracy of $0.08 \mathrm{~N}$ to control strength of joints in an arm exoskeleton [126]. An important element of the bionic upper limb orthosis is the hand grip force measurement, consequently a special sensor was designed for this task [127]. Its purpose is to adjust the hand grip force to prevent damaging the grasped object. For this purpose, a Von Frey hair (a monofilament fibre) was used. Thanks to that, the sensor senses pressure as low as $0.087 \mathrm{~N} / \mathrm{mm}^{2}$. 
Table 4. Sensors used in bionic orthoses.

\begin{tabular}{|c|c|c|c|}
\hline Sensor & Main Advantage & Main Drawback & $\begin{array}{c}\text { Usefulness in Bionic } \\
\text { Orthoses }\end{array}$ \\
\hline Touch sensor & Feedback improvement & Complex & Optional \\
\hline Force/torque sensor & $\begin{array}{c}\text { Could be estimated by the } \\
\text { current }\end{array}$ & $\begin{array}{l}\text { Difficulties in measurement } \\
\text { in dynamic conditions }\end{array}$ & Yes \\
\hline Encoder & Simplicity & Relatively big & Yes \\
\hline Accelerometer & Versatility & $\begin{array}{l}\text { Limited accuracy of } \\
\text { determining device } \\
\text { orientation }\end{array}$ & Yes \\
\hline Inclinometer & Simple posture control & $\begin{array}{l}\text { Usefull in specific } \\
\text { conditions }\end{array}$ & Optional \\
\hline Gyroscope & Precision & $\begin{array}{l}\text { Requires additional } \\
\text { electronics }\end{array}$ & Yes \\
\hline Distance sensor & Protection against breakage & Need to use several sensors & Optional \\
\hline $\begin{array}{l}\text { Camera for shape } \\
\text { recognition }\end{array}$ & $\begin{array}{c}\text { Increases rehabilitation } \\
\text { efficiency }\end{array}$ & Expensive & Optional \\
\hline
\end{tabular}

In research associated with balance assistance of a hip exoskeleton robot the control strategy is based on sensors data as interaction force between exoskeleton and human thigh (force sensors), posture detection (inertial measurement units), ground contact detection (pressure insoles) [128]. Some of these sensors can be successfully implemented in upper-limb orthosis control system.

Some robotic devices can have a camera that recognises shapes using advanced algorithms. Use of the camera is designed to adjust the strength when gripping and lifting objects. The most important tasks of shape recognition algorithms are: extracting the object from the environment, determining the distance and position of the object, and passing this information as soon as possible to the main processor. However, those operations require advanced algorithms and are suitable for stable and repeatable conditions [108].

Virtual Sensors allow to estimate the robot/user interaction force and motion [129]. It is cheaper and equally effective alternative to standard contact force and motion sensors. The Virtual Sensors design is based primarily on position sensors, such as optical encoders or linear potentiometers.

In the case of pneumatic artificial muscle, Tjahyono et al. [130] proposed additional sensors. One of them is a ring entwining the artificial muscle made of a conductive elastomer. It measures changes in electrical conductivity when the pressure in the artificial muscle increases, thus determining the circumference displacement. The other sensor is a carbon-fibre nylon equipped with a sliding electrode and two end-fix electrodes. A sensor of this type is a flexible potentiometer responsible for measuring longitudinal displacement of the artificial muscle. Another example is a polypropylene deformation sensor that measures electrical conductivity (changing with the change of polymer chain length) to obtain information on deformation.

\section{Control System Feedback}

Feedback of different signals was not used in control systems at early exoskeletons development. In those times, robots were built with master/slave control systems. A breakthrough in the field of exoskeleton system control was the use of an interaction force between the human body and the exoskeleton system [131]. Nowadays, most of rehabilitation devices do not use feedback. Instead, they rely only on the physiotherapist's judgement and actions, sometimes being able to pass information about the patient's condition (based on biochemical signals) and current parameters of the device. This situation can be deemed inadequate, because rehabilitation systems should use biochemical signals obtained from the rehabilitated person to adjust their operation. In this case the physiotherapist could only perform a supervisory function (Triggered Passive Control 
Model) [132-136]. For this reason this type of feedback bears often the name of a full biological feedback (Figure 5).

a

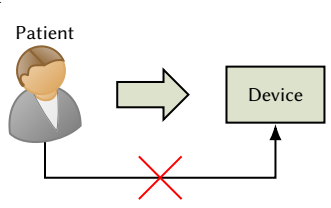

c

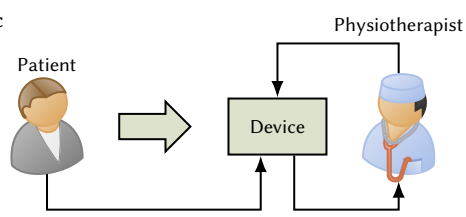

b

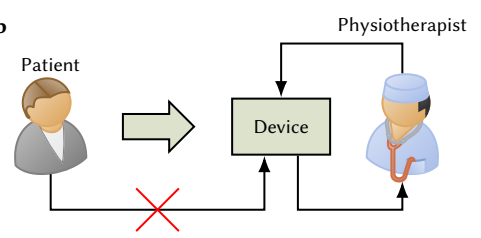

d

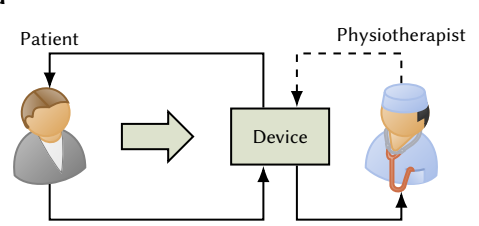

Figure 5. Types of rehabilitation systems: (a,b) no feedback—open loop, (c) classical feedback—closed loop, (d) full biofeedback—closed loop.

There are many measures to register change in a person's physiological state and the most common are: electromyography (EMG), electroencephalography (EEG), electrodermal activity (galvanic skin response-GSR or electrodermal response-EDR), slow cortical potential (SCP), hemoencephalography (HEG), heart rate variability (HRV), respiratory sinus arrhythmia (RSA), as well as other respiratory and temperature biofeedback [27].

The most frequently used signal to recognise stimuli is the EMG. For years, EMG has been used to control an exoskeleton in tasks, like supporting movements [137] or rehabilitation [138]. High efficiency of EMG signals used in control is presented by Palkowski et al. $[139,140]$. However, interferences, which occur during signal processing, can lead to system malfunction. For this reason, different types of filtration are used. The most common of them are: Hilbert transform [141], Fourier transform [142], and continuous wavelet transform [143,144].

EEG is used as a control signals in a brain-computer interface (BCI), which allows the patient to control the rehabilitation process directly by using brain waves. An extensive literature review of EEG-based BCIs has been prepared by [145]. High performance of computer control systems based on EEG has been proven, i.e., by Cantillo-Negrete et al. [146]. The results give hope for faster and more effective rehabilitation for people with cerebral palsy $[147,148]$. Along with many advantages of using EEG to control a bionic orthosis, this method has one basic defect-control is very complex and requires long-term preparation from a patient [149]. Scientists are trying to solve this problem by using hybrid BCI systems [150]. The popularity of EEG as a control signal is increasing, which can be depicted by how many studies are focused on it every year (Figure 6).

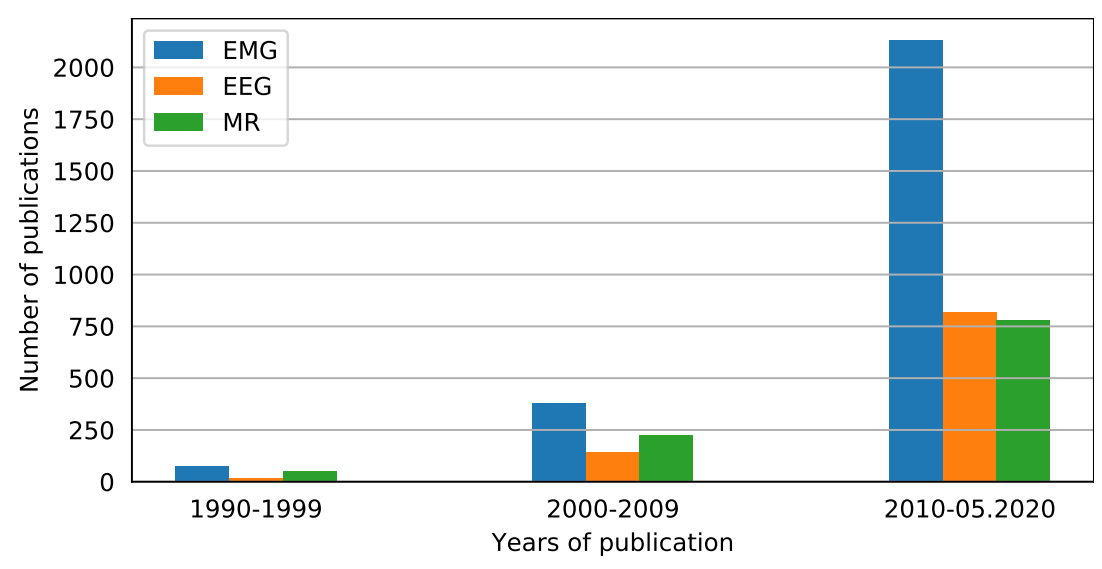

Figure 6. Publications on bionic orthosis control signals. 
A novel control method is the use of neuroimaging by functional magnetic resonance imaging (fMRI). With this method, brain activity can be visualised while performing actions and processed into control signals [96]. At the moment, the method is only a concept and cannot be implemented due to technological limitations. Another way to control a bionic orthosis are signals derived from relative changes in blood flow volume. The data measured by impedance plethysmography are -=the electrical impedance variability caused by the flow of blood through the studied area. The measuring method requires placing at least four electrodes-two voltage and two current electrodes-in the studied area (e.g., the upper limb) [151].

A similar form of medical examination of myocardial function is an electrocardiogram (ECG). ECG records the potential difference between two electrodes located on the torso, being in fact the electrical activity of the myocardium. ECG signals provide a wide range of information on the degree of strain and fatigue of the monitored organism. ECG might be performed with phonocardiography (PCG), which records biomechanical cardiac activity on the basis of sound signals [152]. Reading signals using this method is a simple task and can be done with a simple instrument. In medical research, PCG is not widely used and has not been developed for many years. Its main disadvantage is disturbances detected by the phonocardiograph, which hinder the analysis of the results. However, a method for classifying sound signals was proposed by Redlarski et al. [153], thanks to which the basic defect of the above test can be eliminated. This allows PCG to be successfully used to control a bionic orthosis.

\section{Modern Computer Methods in Medical Engineering}

\subsection{Machine Learning}

Jagodnik et al. [154] demonstrated the use of reinforced learning in rebuilding muscle memory in patients with spinal cord injury who were using functional electrical stimulation (FES). Bionic orthoses can also benefit from machine learning. The idea of using reinforced learning in rehabilitation aims at maximising the effectiveness of the treatment. This is possible thanks to the personalisation of the device, which minimises the impact of bionic orthotics on the patient (appropriate adjustment of force). Celadon et al. [155] compared three methods of machine learning: linear discriminant analysis classifier (LDA), common spatial patterns proportional estimator (CSP-PE), and thresholding algorithm (THR). The aim of that study was to isolate signals from EMG, responsible for the movement of individual fingers of a healthy person, to improve the therapy with rehabilitation robots. The best results, with a small number of electrodes (up to 24), were obtained for the CSP-PE classifier. In another survey, the support vector machine classifier (SVM), improved by the cuckoo search swarm algorithm, was used for hand gesture recognition $[140,156]$. The results turned out to be very satisfying, providing $98.12 \%$ correct classification. Other widely used classification methods are: adaptive neuro-fuzzy inference system (ANFIS) [157], K nearest neighbours algorithm (KNN) [158], and decision tree (DT) [159]. We believe that the use of other machine learning methods like Multilayer Perceptron (MLP) or Random Forest (RF) can be very effective as in the case of our previous research [140,156,160].

A common problem during rehabilitation is the loss of concentration and decrease in engagement during repetitive activities, which can lead to less effective treatment. To overcome this problem, a conceptual measurement and stimulation system of patient engagement (the smart learning mechanism-SLM) was proposed [161]. The SLM made use of comprehensive signal processing systems and machine learning techniques. Regression models based on artificial neural networks and a naive Bayesian classifier (NB) were used in the study to compare performance [161,162], which showed the superiority of the NB method. The NB was less susceptible to deviations of input signals and showed greater accuracy regardless of the number of outputs. However, both methods should be compared experimentally to confirm their suitability. 


\subsection{Multimedia Systems}

The use of multimedia systems is becoming more common in physical rehabilitation. The growing popularity of this solution is associated with research showing the positive effects of this method compared to traditional methods of rehabilitation [163-167]. The use of multimedia systems allows for: increasing immersion going beyond the sphere of physiological sensations (into the sphere of psychological feelings) and to integrate the received sensations using the senses hearing, sight, and touch. The main advantages of using VR in rehabilitation are: increased patient motivation, accuracy of movement mapping, and cognitive fidelity. Focusing on multitasking does not require constant supervision of a physiotherapist, progress monitoring, the option to repeat the same exercise repeatedly checking its correctness and option to save the patient's profile in the system. However, you cannot be completely sure of the effectiveness of using multimedia systems in rehabilitation. In Australia, extensive research was carried out that did not show a significant impact of the use of multimedia systems on the effects of physical rehabilitation [168]. The main conclusion of the effectiveness of the use of multimedia systems in rehabilitation is that therapy should be tailored to the individual patient and there is no ideal solution for each clinical case.

\section{Summary and Conclusions}

The article presents state-of-the-art, medical device regulations and prospects for the development of a mechanical design, actuator technology, sensor systems, control systems, and computer methods in medical engineering. Moreover, current technical solutions, as well as forecasts on improvement, for exoskeletons are presented and reviewed. The review presented might be the cornerstone for future research on advanced rehabilitation engineering technology, such as an upper limb bionic orthosis. All significant elements described in the paper are summarised in Figure 7.

At the current level of mechanical technology development, upper limb bionic orthosis should be constructed in a manner that is as close as possible to the construction of the human limb. For this reason, direct matching of joint centres' mechanism should be used. Depending on the application (cheap and quick to construct or light and durable), the materials adapted to standard 3D printing and carbon fibre should be taken into account as the construction materials. Moreover, the brushless DC motors or artificial muscles for conventional and unconventional drives, respectively, are the best choices for selecting direct matching of joint centres.

Control systems should be based on EMG signals as biofeedback because it allows to create a simple and quick-to-learn bionic orthosis management system with machine learning. Most used machine learning algorithms are characterised by high efficiency in medical engineering and do not take much computational power. Requirements regarding sensors in bionic orthoses are not excessive, but they fulfill an extremely important role in control and ensuring patient safety.

The use of bionic orthoses in rehabilitation will significantly shorten the duration of therapy, contributing to better treatment of limbs. For this reason, the development of exoskeletons used for medical applications is essential. The design of this type of robotic orthoses should be efficient, easy to operate, and compact. There is a possibility of coupling the orthosis with a multimedia system, which will probably significantly improve the effectiveness of treatment. These features are necessary to popularise exoskeletons for rehabilitation applications in the future.

The most important elements for bionic orthoses are: control system, drives, and sensors. Depending on the application of the exoskeleton, other goals should be set: precision of movements, light and compact design, or high power consumption. In the case of bionic orthoses used for rehabilitation, the key features are the precision of the exercise and the ability to adjust the power to the level of fatigue/involvement of the patient. These features will shorten the period of medical care for rehabilitated people. Additionally, advanced control systems can oversee the course of rehabilitation exercises. 


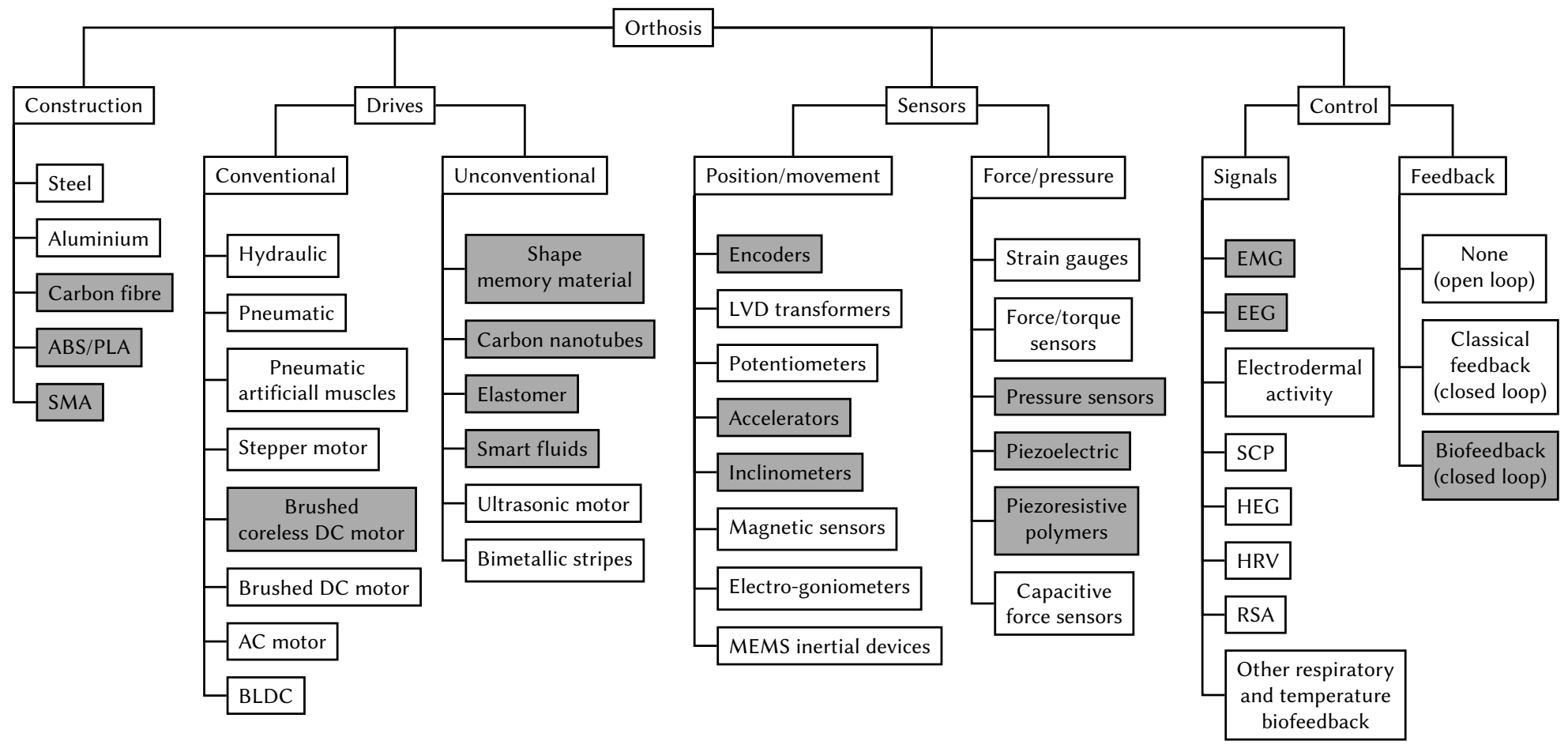

Figure 7. Summary of the main bionic orthosis elements described in the paper. Grey blocks indicate elements that are essential for future development of orthoses. 
The biggest challenge in developing a fully usable rehabilitation orthosis is to hybridize all the systems described. That is an issue that requires further research. Without thorough research it is not possible to determine which solutions will be the most effective. An additional challenge is the individualisation of orthosis with the use of scanners and 3D printers. Taking into account the previously mentioned factors, an optimal solution is sought between a personalized and a universal device. According to the reaserch team, there is only one-the development of a universal drive, sensors and control system and the individual selection of mechanical parts. Thanks to this approach, high patient comfort will be possible and costs will be acceptable for rehabilitation clinics.

Author Contributions: Conceptualization, G.R. (Grzegorz Redlarski) and G.R. (Gustaw Rzyman); methodology, G.R. (Gustaw Rzyman) and J.S.; software, A.P. and G.R. (Gustaw Rzyman); validation, G.R. (Gustaw Rzyman), J.S. and A.P.; formal analysis, G.R. (Gustaw Rzyman) and J.S.; investigation, G.R. (Gustaw Rzyman) and J.S.; resources, G.R. (Gustaw Rzyman) and J.S.; data curation, G.R. (Gustaw Rzyman), J.S. and G.R. (Grzegorz Redlarski); writing-original draft preparation, G.R. (Gustaw Rzyman) and J.S.; writing—review and editing, G.R. (Grzegorz Redlarski); visualization, G.R. (Gustaw Rzyman), J.S. and A.P.; supervision, G.R. (Grzegorz Redlarski); project administration, G.R. (Grzegorz Redlarski); funding acquisition, G.R. (Grzegorz Redlarski) and G.R. (Gustaw Rzyman). All authors have read and agreed to the published version of the manuscript.

Funding: This research received no external funding.

Conflicts of Interest: The authors declare no conflict of interest.

\section{References}

1. Jefferson, G. The Mind of Mechanical Man. BMJ 1949, 1, 1105-1110. [CrossRef] [PubMed]

2. Čapek, K. Rossumovi Univerzální Roboti (Rossum's Universal Robots); Animedia Company: Prague, Czech Republic, 2014; p. 89.

3. Kinyon, K. The Phenomenology of Robots: Confrontations with Death in Karel Čapek's "R.U.R.". Sci. Fict. Stud. 1999, 26, 379-400.

4. Hockstein, N.G.; Gourin, C.G.; Faust, R.A.; Terris, D.J. A history of robots: From science fiction to surgical robotics. J. Robot. Surg. 2007, 1, 113-118. [CrossRef] [PubMed]

5. Andry, N. L'Orthopédie ou l'art de Prévenir et de Corriger dans les Enfans, les Difformités du Corps; Chez La Veuve Alix: Paris, France, 1741; p. 348.

6. Lovett, R.W.; Boston, M.D. The History of Scoliosis. J. Bone Jt. Surg. 1913, 2, 54-62.

7. Fick, B.R.; Makinson, J.B. Final Report on Hardiman I Prototype for Machine Augmentation of Human Strength and Endurance; Technical Report; General Electric Company: New York, NY, USA, 1971.

8. Boldt, K. Three Axis Mechanical Joint for a Power Assist Device. U.S. Patent 5,282,460, 1 February 1994.

9. Salter, R.B.; Hamilton, H.W.; Wedge, J.H.; Tile, M.; Torode, I.P.; O’Driscoll, S.W.; Murnaghan, J.J.; Saringer, J.H. Clinical application of basic research on continuous passive motion for disorders and injuries of synovial joints: A preliminary report of a feasibility study. J. Orthop. Res. 1983, 1, 325-342. [CrossRef]

10. Díaz, I.; Gil, J.J.; Sánchez, E. Lower-Limb Robotic Rehabilitation: Literature Review and Challenges. J. Robot. 2011, 2011. [CrossRef]

11. Lum, P.S.; Burgar, C.G.; Van Der Loos, M.; Shor, P.C.; Majmundar, M.; Yap, R. MIME robotic device for upper-limb neurorehabilitation in subacute stroke subjects: A follow-up study. J. Rehabil. Res. Dev. 2006, 43, 631-642. [CrossRef]

12. Housman, S.J.; Le, V.; Rahman, T.; Sanchez, R.J.; Remkensrneyer, D.J. Arm-training with T-WREX after chronic stroke: Preliminary results of a randomized controlled trial. In Proceedings of the 2007 IEEE 10th International Conference on Rehabilitation Robotics (ICORR '07), Noordwijk, The Netherlands, 13-15 June 2007; pp. 562-568. [CrossRef]

13. Roceso. Arm and Hand Rehabilitation Devices; Roceso Technologies: Singapore, 2020.

14. Bioservo. Keeping People Strong Healthy and Motivated; Bioservo Technologies: Kista, Sweden, 2020.

15. Myomo. Medical Robotics Solutions for Stroke, BPI, Upper Limb Paralysis; Myomo: Cambridge, MA, USA, 2020.

16. Brokaw, E.B.; Black, I.; Holley, R.J.; Lum, P.S. Hand Spring Operated Movement Enhancer (HandSOME): A Portable, Passive Hand Exoskeleton for Stroke Rehabilitation. IEEE Trans. Neural Syst. Rehabil. Eng. 2011, 19, 391-399. [CrossRef] 
17. Gassert, R.; Dietz, V. Rehabilitation robots for the treatment of sensorimotor deficits: A neurophysiological perspective. J. NeuroEng. Rehabil. 2018, 15, 46. [CrossRef]

18. Farmer, S.E.; Durairaj, V.; Swain, I.; Pandyan, A.D. Assistive Technologies: Can They Contribute to Rehabilitation of the Upper Limb After Stroke? Arch. Phys. Med. Rehabil. 2014, 95, 968-985. [CrossRef]

19. Prange, G.B.; Jannink, M.J.a.; Groothuis-Oudshoorn, C.G.M.; Hermens, H.J.; IJzerman, M.J. Systematic review of the effect of robot-aided therapy on recovery of the hemiparetic arm after stroke. J. Rehabil. Res. Dev. 2006, 43, 171-184. [CrossRef] [PubMed]

20. Frisoli, A.; Procopio, C.; Chisari, C.; Creatini, I.; Bonfiglio, L.; Bergamasco, M.; Rossi, B.; Carboncini, M. Positive effects of robotic exoskeleton training of upper limb reaching movements after stroke. J. NeuroEng. Rehabil. 2012, 9, 36. [CrossRef]

21. Kwakkel, G.; Kollen, B.J.; Krebs, H.I. Effects of Robot-Assisted Therapy on Upper Limb Recovery after Stroke: A Systematic Review. Neurorehabil. Neural Repair 2008, 22, 111-121. [CrossRef] [PubMed]

22. Xu, G.; Song, A.; Pan, L.; Li, H.; Liang, Z.; Zhu, S.; Xu, B.; Li, J. Adaptive Hierarchical Control for the Muscle Strength Training of Stroke Survivors in Robot-aided Upper-limb Rehabilitation. Int. J. Adv. Robot. Syst. 2012, 9, 1. [CrossRef]

23. Burgar, C.G.; Lum, P.S.; Shor, P.C.; Machiel Van der Loos, H.F. Development of robots for rehabilitation therapy: The Palo Alto VA/Stanford experience. J. Rehabil. Res. Dev. 2000, 37, 647-663.

24. Tomić, T.J.D.; Savić, A.M.; Vidaković, A.S.; Rodić, S.Z.; Isaković, M.S.; Rodríguez-de Pablo, C.; Keller, T.; Konstantinović, L.M. ArmAssist Robotic System versus Matched Conventional Therapy for Poststroke Upper Limb Rehabilitation: A Randomized Clinical Trial. BioMed Res. Int. 2017, 2017. [CrossRef] [PubMed]

25. Wu, Q.; Wu, H. Development, Dynamic Modeling, and Multi-Modal Control of a Therapeutic Exoskeleton for Upper Limb Rehabilitation Training. Sensors 2018, 18, 3611. [CrossRef] [PubMed]

26. Zhang, S.; Fu, Q.; Guo, S.; Fu, Y. Coordinative Motion-based Bilateral Rehabilitation Training System with Exoskeleton and Haptic Devices for Biomedical Application. Micromachines 2018, 10, 8. [CrossRef]

27. Rahman, M.H.; Rahman, M.J.; Cristobal, O.L.; Saad, M.; Kenné, J.P.; Archambault, P.S. Development of a whole arm wearable robotic exoskeleton for rehabilitation and to assist upper limb movements. Robotica 2015, 33, 19-39. [CrossRef]

28. Available online: https:/ / myomo.com/what-is-a-myopro-orthosis/ (accessed on 29 June 2020).

29. Available online: https://www.shutterstock.com/pl/image-photo/patient-on-cpm-continuous-passiverange-1154961649?fbclid=IwAR09jNTzgSIUafTXdMD-6aOrUawSfCI_dyw959PKIEDFoB2qviJKBjjc8iM (accessed on 29 June 2020).

30. U.S. Food and Drug Administration. Overview of Device Regulation; FDA: Silver Spring, MD, USA, 2011.

31. Japan Quality Assurance Organization. Overview I Pharmaceuticals and Medical Device Law (PMDL) (Mandatory Medical Device Approval) I Mandatory Approvals | Testing and Certification of Electrical and Electronic Products; JQA: Tokyo, Japan, 2020.

32. Fikriah, N.S.; Saripan, H.; Ismail, Z. The Medical Device Regulation for Humanoid Robotics: Does One Size Fits All? Procedia Comput. Sci. 2015, 76, 381-387. [CrossRef]

33. Food and Drug Administration. Factors to Consider Regarding BenefitRisk in Medical Device Product Availability, Compliance, and Enforcement Decisions; Food and Drug Administration: Muntinlupa, Philippines, 2016.

34. Tamura, A. Understanding Japanese Medical Device Requirements. In 2011 AHC Workshop on Medical Devices: Implementation of GHTF Documents; Asian-Pacific Economic Cooperation: Seoul, Korea, 2011.

35. Ciarkowski, A.A. FDA regulatory requirements for medical devices with control algorithms. In Proceedings of the 2000 American Control Conference ACC (IEEE Cat. No.00CH36334), Chicago, IL, USA, 28-30 June 2000; Volume 5, pp. 3497-3500. [CrossRef]

36. The Council of the European Communities. Council Directive 93/42/EEC of 14 June 1993 Concerning Medical Devices; The Council of the European Communities: Brussels, Belgium, 1993.

37. U.S. Government Printing Office. eCFR-Code of Federal Regulations. In Electronic Code of Federal Regulations; U.S. Government Printing Office: Washington, DC, USA, 2010.

38. Sejm Rzeczypospolitej Polskiej. Ustawa o Wyrobach Medycznych; Sejm Rzeczypospolitej Polskiej: Warsaw, Poland, 2018.

39. European Commission. Dyrektywa Maszynowa; European Commission: Brussels, Belgium, 2006. 
40. European Commision. Council Directive 73/23/EEC of 19 February 1973 on the Harmonization of the Laws of Member States Relating to Electrical Equipment Designed for Use within Certain Voltage Limits; European Commission: Brussels, Belgium, 1973.

41. ISO/TC 299. IEC 80601-2-78:2019. In Medical Electrical Equipment_Part 2-78: Particular Requirements for Basic Safety and Essential Performance of Medical Robots for Rehabilitation, Assessment, Compensation or Alleviation; ISO: Geneva, Switzerland, 2019.

42. Chen, C.W.; Lin, C.C.K.; Ju, M.S. Hand orthosis controlled using brain-computer interface. J. Med. Biol. Eng. 2009, 29, 234-241.

43. Rupp, R.; Rohm, M.; Schneiders, M.; Kreilinger, A.; Muller-Putz, G.R. Functional Rehabilitation of the Paralyzed Upper Extremity After Spinal Cord Injury by Noninvasive Hybrid Neuroprostheses. Proc. IEEE 2015, 103, 954-968. [CrossRef]

44. Vorobyev, A.A.; Andryushchenko, F.A.; Ponomareva, O.A.; Solovyeva, I.O.; Krivonozhkina, P.S. The Development and Clinical Testing of "EXAR", Passive Upper Limb Exoskeleton. Sovrem. Tehnol. Med. 2016, 8, 90-97. [CrossRef]

45. Wang, F.; Zhang, X.; Fu, R.; Sun, G. Study of the Home-Auxiliary Robot Based on BCI. Sensors 2018, 18, 1779. [CrossRef]

46. Tang, Z.; Sun, S.; Zhang, S.; Chen, Y.; Li, C.; Chen, S. A Brain-Machine Interface Based on ERD/ERS for an Upper-Limb Exoskeleton Control. Sensors 2016, 16, 2050. [CrossRef] [PubMed]

47. Chaudhary, U.; Birbaumer, N.; Ramos-Murguialday, A. Brain-computer interfaces for communication and rehabilitation. Nat. Rev. Neurol. 2016, 12, 513-525. [CrossRef] [PubMed]

48. Wairagkar, M.; Zoulias, I.; Oguntosin, V.; Hayashi, Y.; Nasuto, S. Movement intention based Brain Computer Interface for Virtual Reality and Soft Robotics rehabilitation using novel autocorrelation analysis of EEG. In Proceedings of the 2016 6th IEEE International Conference on Biomedical Robotics and Biomechatronics (BioRob), Singapore, 26-29 June 2016; p. 685.

49. Fleischer, C.; Hommel, G. A Human-Exoskeleton Interface Utilizing Electromyography. IEEE Trans. Robot. 2008, 24, 872-882. [CrossRef]

50. Struktura i własności stali 316L. 2007. Available online: http:/ / www.stalenierdzewne.pl/1092/struktura-iwlasnosci-stali-3161 (accessed on 29 June 2020).

51. Maciejasz Pawełand Eschweiler, J.; Gerlach-Hahn, K.; Jansen-Troy, A.; Leonhardt, S. A survey on robotic devices for upper limb rehabilitation. J. NeuroEng. Rehabil. 2014, 11, 3. [CrossRef]

52. Bos, R.A.; Haarman, C.J.W.; Stortelder, T.; Nizamis, K.; Herder, J.L.; Stienen, A.H.A.; Plettenburg, D.H. A structured overview of trends and technologies used in dynamic hand orthoses. J. NeuroEng. Rehabil. 2016, 13, 62. [CrossRef]

53. Biagiotti, L.; Lotti, F.; Melchiorri, C.; Vassura, G. How Far Is the Human Hand? Technical Report; University of Bologna: Bologna, Italy, 2004.

54. Controzzi, M.; Cipriani, C.; Carrozza, M.C. Design of artificial hands: A review. In The Human Hand as an Inspiration for Robot Hand Development; Springer: Cham, Switzerland, 2014; Volume 95, pp. 219-246. [CrossRef]

55. Grebenstein, M.; Albu-Schäffer, A.; Bahls, T.; Chalon, M.; Eiberger, O.; Friedl, W.; Gruber, R.; Haddadin, S.; Hagn, U.; Haslinger, R.; et al. The DLR hand arm system. In Proceedings of the 2011 IEEE International Conference on Robotics and Automation, Shanghai, China, 9-13 May 2011; pp. 3175-3182. [CrossRef]

56. Bridgwater, L.B.; Ihrke, C.A.; Diftler, M.A.; Abdallah, M.E.; Radford, N.A.; Rogers, J.M.; Yayathi, S.; Askew, R.S.; Linn, D.M. The robonaut 2 hand-Designed to do work with tools. In Proceedings of the 2012 IEEE International Conference on Robotics and Automation, Saint Paul, MN, USA, 14-18 May 2012; pp. 3425-3430. [CrossRef]

57. Yoshikawa, M.; Sato, R.; Higashihara, T.; Ogasawara, T.; Kawashima, N. Rehand: Realistic electric prosthetic hand created with a 3D printer. In Proceedings of the 2015 37th Annual International Conference of the IEEE Engineering in Medicine and Biology Society (EMBC), Milan, Italy, 25-29 August 2015; Volume 40, pp. 2470-2473. [CrossRef]

58. Heo, P.; Gu, G.M.; Lee, S.j.; Rhee, K.; Kim, J. Current hand exoskeleton technologies for rehabilitation and assistive engineering. Int. J. Precis. Eng. Manuf. 2012, 13, 807-824. [CrossRef]

59. Iqbal, J.; Khan, H.; Tsagarakis, N.G.; Caldwell, D.G. A novel exoskeleton robotic system for hand rehabilitation-Conceptualization to prototyping. Biocybern. Biomed. Eng. 2014, 34, 79-89. [CrossRef] 
60. Wege, A.; Hommel, G. Development and control of a hand exoskeleton for rehabilitation of hand injuries. In Proceedings of the 2005 IEEE/RSJ International Conference on Intelligent Robots and Systems (IROS), Edmonton, AB, Canada, 2-6 August 2005; pp. 3461-3466. [CrossRef]

61. Ueki, S.; Kawasaki, H.; Ito, S.; Nishimoto, Y.; Abe, M.; Aoki, T.; Ishigure, Y.; Ojika, T.; Mouri, T. Development of a hand-assist robot with multi-degrees-of-freedom for rehabilitation therapy. IEEE/ASME Trans. Mechatron. 2012, 17, 136-146. [CrossRef]

62. Shields, B.L.; Main, J.A.; Peterson, S.W.; Strauss, A.M. An anthropomorphic hand exoskeleton to prevent astronaut hand fatigue during extravehicular activities. IEEE Trans. Syst. Man Cybern. Part A Syst. Hum. 1997, 27, 668-673. [CrossRef] [PubMed]

63. In, H.K.; Cho, K.J.; Kim, K.R.; Lee, B.S. Jointless structure and under-actuation mechanism for compact hand exoskeleton. In Proceedings of the IEEE International Conference on Rehabilitation Robotics, Zurich, Switzerland, 29 June-1 July 2011. [CrossRef]

64. In, H.K.; Cho, K.J. Evaluation of the antagonistic tendon driven system for SNU Exo-Glove. In Proceedings of the 2012 9th International Conference on Ubiquitous Robots and Ambient Intelligence (URAI 2012), Daejeon, South Korea, 26-28 November 2012; pp. 507-509. [CrossRef]

65. Cempini, M.; Cortese, M.; Vitiello, N. A powered finger-thumb wearable hand exoskeleton with self-aligning joint axes. IEEE/ASME Trans. Mechatron. 2015, 20, 705-716. [CrossRef]

66. Baker, M.D.; McDonough, M.K.; McMullin, E.M.; Swift, M.; BuSha, B.F. Orthotic hand-assistive exoskeleton. In Proceedings of the 2011 IEEE 37th Annual Northeast Bioengineering Conference (NEBEC), Troy, NY, USA, 1-3 April 2011. [CrossRef]

67. Saebo Incorporated. SaeboFlex; Saebo Incorporated: Charlotte, NC, USA, 2020.

68. Rakib, M.I.; Choudhury, I.A.; Hussain, S.; Osman, N.A.A. Design and biomechanical performance analysis of a user-friendly orthotic device. Mater. Des. (1980-2015) 2015, 65, 716-725. [CrossRef]

69. The Aluminum Association Inc.. International Alloy Designations and Chemical Composition Limits for Wrought Aluminum and Wrought Aluminum Alloys; Technical Report; Arlington: Quezon City, Philippines, 2006.

70. Zhang, R.X.; Ni, Q.Q.; Natsuki, T.; Iwamoto, M. Mechanical properties of composites filled with SMA particles and short fibers. Compos. Struct. 2007, 79, 90-96. [CrossRef]

71. Madden, J.D.W.; Vandesteeg, N.A.; Anquetil, P.A.; Madden, P.G.A.; Takshi, A.; Pytel, R.Z.; Lafontaine, S.R.; Wieringa, P.A.; Hunter, I.W. Artificial Muscle Technology: Physical Principles and Naval Prospects. IEEE J. Ocean. Eng. 2004, 29, 706-728. [CrossRef]

72. JASZKIEWICZ, A.; BLEDZKI, A.K.; FRANCISZCZAK, P. Improving the mechanical performance of PLA composites with natural, man-made cellulose and glass fibers-A comparison to PP counterparts. Polimery 2013, 58, 435-442. [CrossRef]

73. Duda, A.; Penczek, S. Polilaktyd [poli(kwas mlekowy)]: synteza, właściwości i zastosowania. Polimery 2003, 48, 16-27. [CrossRef]

74. Cantrell, J.T.; Rohde, S.; Damiani, D.; Gurnani, R.; DiSandro, L.; Anton, J.; Young, A.; Jerez, A.; Steinbach, D.; Kroese, C.; et al. Experimental characterization of the mechanical properties of 3D-printed ABS and polycarbonate parts. Rapid Prototyp. J. 2017, 23, 811-824. [CrossRef]

75. Artemenko, S.E.; Kadykova, Y.A. Polymer composite materials based on carbon, basalt, and glass fibres. Fibre Chem. 2008, 40, 30-32. [CrossRef]

76. Concilio, A.; Lecce, L. Shape Memory Alloy Engineering: For Aerospace, Structural and Biomedical Applications; Elsevier: Oxford, UK, 2014; p. 448.

77. Gupta, A.; O'Malley, M.K. Design of a haptic arm exoskeleton for training and rehabilitation. IEEE/ASME Trans. Mechatron. 2006, 11, 280-289. [CrossRef]

78. Baronio, G.; Harran, S.; Signoroni, A. A Critical Analysis of a Hand Orthosis Reverse Engineering and 3D Printing Process. Appl. Bionics Biomech. 2016, 2016, 8347478. [CrossRef] [PubMed]

79. Cui, L.; Phan, A.; Allison, G. Design and fabrication of a three dimensional printable non-assembly articulated hand exoskeleton for rehabilitation. In Proceedings of the 2015 37th Annual International Conference of the IEEE Engineering in Medicine and Biology Society (EMBC), Milan, Italy, 25-29 August 2015; pp. 4627-4630.

80. Bataller, A.; Cabrera, J.A.; Clavijo, M.; Castillo, J.J. Evolutionary synthesis of mechanisms applied to the design of an exoskeleton for finger rehabilitation. Mech. Mach. Theory 2016, 105, 31-43. [CrossRef] 
81. Agarwal, P.; Neptune, R.R.; Deshpande, A.D. A Simulation Framework for Virtual Prototyping of Robotic Exoskeletons. J. Biomech. Eng. 2016, 138, 61004. [CrossRef] [PubMed]

82. Conti, R.; Meli, E.; Ridolfi, A. A novel kinematic architecture for portable hand exoskeletons. Mechatronics 2016, 35, 192-207. [CrossRef]

83. Zuniga, J.; Katsavelis, D.; Peck, J.; Stollberg, J.; Petrykowski, M.; Carson, A.; Fernandez, C. Cyborg beast: A low-cost 3d-printed prosthetic hand for children with upper-limb differences. BMC Res. Notes 2015, 8, 10. [CrossRef]

84. Silva, K.; Rand, S.; Cancel, D.; Chen, Y.; Kathirithamby, R.; Stern, M. Three-Dimensional (3-D) Printing: A Cost-Effective Solution for Improving Global Accessibility to Prostheses. PMER 2015, 7, 1312-1314.

85. Gopura, R.; Bandara, D.S.V.; Kiguchi, K.; Mann, G.K.I. Developments in hardware systems of active upper-limb exoskeleton robots: A review. Robot. Auton. Syst. 2016, 75, 203-220. [CrossRef]

86. Veale, A.J.; Xie, S.Q. Towards compliant and wearable robotic orthoses: A review of current and emerging actuator technologies. Med. Eng. Phys. 2016, 38, 317-325. [CrossRef]

87. Kalantari, O.; Ghaffari, A.S. Prototype Construction of the Wearable Soft Orthotic Exoskeleton for Upper Limb Rehabilitation of Post-Stroke Patients. J. Life Sci. Technol. 2016. [CrossRef]

88. Bogue, R. Robotic exoskeletons: A review of recent progress. Ind. Robot Int. J. 2015, 42, 5-10. [CrossRef]

89. Stewart, A.M.; Pretty, C.G.; Adams, M.; Chen, X. Review of Upper Limb Hybrid Exoskeletons. IFAC-PapersOnLine 2017, 50, 15169-15178. [CrossRef]

90. Shahid, T.; Gouwanda, D.; Nurzaman, S.G.; Gopalai, A.A. Moving toward Soft Robotics: A Decade Review of the Design of Hand Exoskeletons. Biomimetics 2018, 3, 17. [CrossRef] [PubMed]

91. Mirvakili, S.M.; Hunter, I.W. Artificial Muscles: Mechanisms, Applications, and Challenges. Adv. Mater. 2018, 30. [CrossRef] [PubMed]

92. López-Larraz, E.; Trincado-Alonso, F.; Rajasekaran, V.; Pérez-Nombela, S.; Del-Ama, A.J.; Aranda, J.; Minguez, J.; Gil-Agudo, A.; Montesano, L. Control of an Ambulatory Exoskeleton with a Brain-Machine Interface for Spinal Cord Injury Gait Rehabilitation. Front. Neurosci. 2016, 10, 359. [CrossRef] [PubMed]

93. Tran, H.T.; Cheng, H.; Rui, H.; Lin, X.; Duong, M.K.; Chen, Q. Evaluation of a Fuzzy-Based Impedance Control Strategy on a Powered Lower Exoskeleton. Int. J. Soc. Robot. 2016, 8, 103-123. [CrossRef]

94. Guan, X.; Ji, L.; Wang, R. Development of Exoskeletons and Applications on Rehabilitation. MATEC Web Conf. 2016, 40, 2004. [CrossRef]

95. Yun, D.; Khan, A.M.; Yan, R.J.; Ji, Y.; Jang, H.; Iqbal, J.; Zuhaib, K.M.; Ahn, J.Y.; Han, J.; Han, C. Handling subject arm uncertainties for upper limb rehabilitation robot using robust sliding mode control. Int. J. Precis. Eng. Manuf. 2016, 17, 355-362. [CrossRef]

96. Sergi, F.; Erwin, A.C.; OMalley, M.K. Interaction Control Capabilities of an MR-Compatible Compliant Actuator for Wrist Sensorimotor Protocols During fMRI. IEEE/ASME Trans. Mechatron. 2015, 20, 2678-2690. [CrossRef]

97. Ates, S.; Mora-Moreno, I.; Wessels, M.; Stienen, A.H.A. Combined active wrist and hand orthosis for home use: Lessons learned. In Proceedings of the 2015 IEEE International Conference on Rehabilitation Robotics (ICORR), Singapore, 11-14 August 2015; pp. 398-403.

98. Ripel, T.; Krejsa, J.; Hrbacek, J.; Cizmar, I. Active Elbow Orthosis. Int. J. Adv. Robot. Syst. 2014, $11,1$. [CrossRef]

99. Bancud, K.; Kutilek, P.; Krivanek, V. Design of powered wearable elbow brace for rehabilitation applications at clinic and home. In Proceedings of the 2019 European Conference on Mobile Robots (ECMR), Prague, Czech Republic, 4-6 September 2019. [CrossRef]

100. Ben, I.A.; Bouteraa, Y.; Rekik, C. Design and development of 3D printed myoelectric robotic exoskeleton for hand rehabilitation. Int. J. Smart Sens. Intell. Syst. 2017, 10, 341-366. [CrossRef]

101. Manian, Y.; Modi, S.; Chandak, T.; Gupta, S.; Sheeba, P.S. Exoskeleton Arm with Pneumatic Muscle Actuation. Int. J. Adv. Eng. Innov. Technol. (IJAEIT) 2014, pp. 4-10.

102. Groenhuis, V.; Chandrapal, M.; Stramigioli, S.; Chen, X. Controlling pneumatic artificial muscles in exoskeletons with surface electromyography. In Proceedings of the 14th Mechatronics Forum International Conference (Mechatronics 2014), Karlstad, Sweden, 6-18 June 2014; pp. 451-457.

103. Ba, D.X.; Dinh, T.Q.; Ahn, K.K. An Integrated Intelligent Nonlinear Control Method for a Pneumatic Artificial Muscle. IEEE/ASME Trans. Mechatron. 2016, 21, 1835-1845. [CrossRef] 
104. Andrikopoulos, G.; Nikolakopoulos, G.; Manesis, S. Advanced Nonlinear PID-Based Antagonistic Control for Pneumatic Muscle Actuators. IEEE Trans. Ind. Electron. 2014, 61, 6926-6937. [CrossRef]

105. Williams, M.R.; Walter, W. Development of a prototype over-actuated biomimetic prosthetic hand. PLoS ONE 2015, 10, e0118817. [CrossRef]

106. FESTO. Fluidic Muscle DMSP/MAS; FESTO: Esslingen, Germany, 2017.

107. Schabowsky, C.N.; Godfrey, S.B.; Holley, R.J.; Lum, P.S. Development and pilot testing of HEXORR: hand EXOskeleton rehabilitation robot. J. NeuroEng. Rehabil. 2010, 7, 36. [CrossRef]

108. Edwards, R.; Lanfontant, K.; Sujumnong, N.; Wormley, J. Vision-Based Intelligent Prosthetic Robotic Arm; Technical Report; Worcester Polytechnic Institute: Worcester, MA, USA, 2009.

109. Zhang, J.; Yin, Y. SMA-based bionic integration design of self-sensor-actuator-structure for artificial skeletal muscle. Sens. Actuators A Phys. 2012, 181, 94-102. [CrossRef]

110. Zhao, H.; Jalving, J.; Huang, R.; Knepper, R.; Ruina, A.; Shepherd, R. A Helping Hand: Soft Orthosis with Integrated Optical Strain Sensors and EMG Control. IEEE Robot. Autom. Mag. 2016, 23, 55-64. [CrossRef]

111. Wang, T.; Farajollahi, M.; Choi, Y.S.; Lin, I.T.; Marshall, J.E.; Thompson, N.M.; Kar-Narayan, S.; Madden, J.D.W.; Smoukov, S.K. Electroactive polymers for sensing. Interface Focus 2016, 6, 20160026. [CrossRef]

112. Benslimane, M.Y.; Kiil, H.E.; Tryson, M.J. Dielectric electro-active polymer push actuators: Performance and challenges. Polym. Int. 2010, 59, 415-421. [CrossRef]

113. Brochu, P.; Pei, Q. Advances in Dielectric Elastomers for Actuators and Artificial Muscles. Macromol. Rapid Commun. 2010, 31, 10-36. [CrossRef] [PubMed]

114. Sinha, N.; Yeow, J.W. Carbon Nanotubes for Biomedical Applications. IEEE Trans. Nanobiosci. 2005, 4, 180-195. [CrossRef] [PubMed]

115. Unluhisarcikli, O.; Weinberg, B.; Sivak, M.; Mirelman, A.; Bonato, P.; Mavroidis, C. A robotic hand rehabilitation system with interactive gaming using novel Electro-Rheological Fluid based actuators. In Proceedings of the 2010 IEEE International Conference on Robotics and Automation, Anchorage, AK, USA, 3-7 May 2010; pp. 1846-1851.

116. Winter, S.H.; Bouzit, M. Use of Magnetorheological Fluid in a Force Feedback Glove. IEEE Trans. Neural Syst. Rehabil. Eng. 2007, 15, 2-8. [CrossRef]

117. Rocon, E.; Belda-Lois, J.M.; Ruiz, A.F.; Manto, M.; Moreno, J.C.; Pons, J.L. Design and Validation of a Rehabilitation Robotic Exoskeleton for Tremor Assessment and Suppression. IEEE Trans. Neural Syst. Rehabil. Eng. 2007, 15, 367-378. [CrossRef]

118. Tai, K.; El-Sayed, A.R.; Shahriari, M.; Biglarbegian, M.; Mahmud, S. State of the Art Robotic Grippers and Applications. Robotics 2016, 5, 11. [CrossRef]

119. Kim, K. A novel method of manufacturing three-dimensional ionic polymer-metal composites (IPMCs) biomimetic sensors, actuators and artificial muscles. Polymer 2002, 43, 797-802. [CrossRef]

120. Gendron, D.; Bubak, G.; Ceseracciu, L.; Ricciardella, F.; Ansaldo, A.; Ricci, D. Significant strain and force improvements of single-walled carbon nanotube actuator: A metal chalcogenides approach. Sens. Actuators B Chem. 2016, 230, 673-683. [CrossRef]

121. Yu, M.F. Strength and Breaking Mechanism of Multiwalled Carbon Nanotubes Under Tensile Load. Science 2000, 287, 637-640. [CrossRef]

122. Cura, V.O.D.; Cunha, F.L.; Aguiar, M.L.; Cliquet, A., Jr. Study of the Different Types of Actuators and Mechanisms for Upper Limb Prostheses. Artif. Organs 2003, 27, 507-516. [CrossRef]

123. Lee, H.; Kim, W.; Han, J.; Han, C. The technical trend of the exoskeleton robot system for human power assistance. Int. J. Precis. Eng. Manuf. 2012, 13, 1491-1497. [CrossRef]

124. Kumar, S.; Wöhrle, H.; Trampler, M.; Simnofske, M.; Peters, H.; Mallwitz, M.; Kirchner, E.; Kirchner, F. Modular Design and Decentralized Control of the Recupera Exoskeleton for Stroke Rehabilitation. Appl. Sci. 2019, 9, 626. [CrossRef]

125. Wege, A.; Kondak, K.; Hommel, G. Mechanical design and motion control of a hand exoskeleton for rehabilitation. In Proceedings of the 2005 IEEE International Conference Mechatronics and Automation, Niagara Falls, ON, Canada, 29 July-1 August 2005; Volume 1, pp. 155-159.

126. Xu, K.; Zhao, J.; Qiu, D.; Wang, Y. A Pilot Study of a Continuum Shoulder Exoskeleton for Anatomy Adaptive Assistances. J. Mech. Robot. 2014, 6, 41011. [CrossRef] 
127. Edin, B.B.; Ascari, L.; Beccai, L.; Roccella, S.; Cabibihan, J.J.; Carrozza, M.C. Bio-inspired sensorization of a biomechatronic robot hand for the grasp-and-lift task. Brain Res. Bull. 2008, 75, 785-795. [CrossRef] [PubMed]

128. Zha, F.; Sheng, W.; Guo, W.; Qiu, S.; Wang, X.; Chen, F.; Zha, F.; Sheng, W.; Guo, W.; Qiu, S.; et al. The Exoskeleton Balance Assistance Control Strategy Based on Single Step Balance Assessment. Appl. Sci. 2019, 9, 884. [CrossRef]

129. Mancisidor, A.; Zubizarreta, A.; Cabanes, I.; Portillo, E.; Jung, J. Virtual Sensors for Advanced Controllers in Rehabilitation Robotics. Sensors 2018, 18, 785. [CrossRef]

130. Tjahyono, A.P.; Aw, K.C.; Devaraj, H.; Surendra, W.; Haemmerle, E.; Travas-Sejdic, J. A five-fingered hand exoskeleton driven by pneumatic artificial muscles with novel polypyrrole sensors. Ind. Robot Int. J. 2013, 40, 251-260. [CrossRef]

131. Kazerooni, H. The human power amplifier technology at the University of California, Berkeley. Robot. Auton. Syst. 1996, 19, 179-187. [CrossRef]

132. Proietti, T.; Crocher, V.; Roby-Brami, A.; Jarrasse, N. Upper-Limb Robotic Exoskeletons for Neurorehabilitation: A Review on Control Strategies. IEEE Rev. Biomed. Eng. 2016, 9, 4-14. [CrossRef]

133. Sakurada, T.; Kawase, T.; Takano, K.; Komatsu, T.; Kansaku, K. A BMI-based occupational therapy assist suit: asynchronous control by SSVEP. Front. Neurosci. 2013, 7, 172. [CrossRef]

134. Frisoli, A.; Loconsole, C.; Leonardis, D.; Banno, F.; Barsotti, M.; Chisari, C.; Bergamasco, M. A New Gaze-BCI-Driven Control of an Upper Limb Exoskeleton for Rehabilitation in Real-World Tasks. IEEE Trans. Syst. Man Cybern. Part C (Appl. Rev.) 2012, 42, 1169-1179. [CrossRef]

135. Barsotti, M.; Leonardis, D.; Loconsole, C.; Solazzi, M.; Sotgiu, E.; Procopio, C.; Chisari, C.; Bergamasco, M.; Frisoli, A. A full upper limb robotic exoskeleton for reaching and grasping rehabilitation triggered by MI-BCI. In Proceedings of the 2015 IEEE International Conference on Rehabilitation Robotics (ICORR), Singapore, 11-14 August 2015; pp. 49-54.

136. Brauchle, D.; Vukelić, M.; Bauer, R.; Gharabaghi, A. Brain state-dependent robotic reaching movement with a multi-joint arm exoskeleton: combining brain-machine interfacing and robotic rehabilitation. Front. Hum. Neurosci. 2015, 9, 564. [CrossRef] [PubMed]

137. Lucas, L.; Dicicco, M.; Matsuoka, Y. An EMG-Controlled Hand Exoskeleton for Natural Pinching. J. Robot. Mechatron. 2004, 16, 1-7. [CrossRef]

138. Leonardis, D.; Barsotti, M.; Loconsole, C.; Solazzi, M.; Troncossi, M.; Mazzotti, C.; Castelli, V.P.; Procopio, C.; Lamola, G.; Chisari, C.; et al. An EMG-controlled robotic hand exoskeleton for bilateral rehabilitation. IEEE Trans. Haptics 2015, 8, 140-151. [CrossRef] [PubMed]

139. Palkowski, A.; Redlarski, G.; Rzyman, G.; Krawczuk, M. Basic evaluation of limb exercises based on electromyography and classification methods. In Proceedings of the 2018 International Interdisciplinary PhD Workshop (IIPhDW), Swinoujscie, Poland, 9-12 May 2018; pp. 323-325.

140. Palkowski, A.; Redlarski, G. Basic Hand Gestures Classification Based on Surface Electromyography. Comput. Math. Methods Med. 2016, 2016, 6481282. [CrossRef]

141. Biagetti, G.; Crippa, P.; Curzi, A.; Orcioni, S.; Turchetti, C. Analysis of the EMG Signal During Cyclic Movements Using Multicomponent AM-FM Decomposition. IEEE J. Biomed. Health Inform. 2015, 19, 1672-1681. [CrossRef] [PubMed]

142. Wang, S.; Gao, Y.; Zhu, Y.; Zhao, J. Estimation of pathological tremor from recorded signals based on adaptive sliding fast Fourier transform. Adv. Mech. Eng. 2016, 8, 1-12. [CrossRef]

143. Gradolewski, D.; Tojza, P.M.; Jaworski, J.; Ambroziak, D.; Redlarski, G.; Krawczuk, M. Arm EMG Wavelet-Based Denoising System. In Advances in Intelligent Systems and Computing; Springer: Cham, Switzerland, 2015; Volume 317, pp. 289-296.

144. Majdalawieh, O.; Gu, J.; Bai, T.; Cheng, G. Biomedical signal processing and rehabilitation engineering: A review. In Proceedings of the 2003 IEEE Pacific Rim Conference on Communications Computers and Signal Processing (PACRIM 2003) (Cat. No.03CH37490), Victoria, BC, Canada, 28-30 August 2003; Volume 2, pp. 1004-1007.

145. Lotte, F.; Bougrain, L.; Cichocki, A.; Clerc, M.; Congedo, M.; Rakotomamonjy, A.; Yger, F. A review of classification algorithms for EEG-based brain-computer interfaces: A 10 year update. J. Neural Eng. 2018, 15, 31005. [CrossRef] 
146. Cantillo-Negrete, J.; Carino-Escobar, R.; Elias-Vinas, D.; Gutierrez-Martinez, J. Control signal for a mechatronic hand orthosis aimed for neurorehabilitation. In Proceedings of the 2015 Pan American Health Care Exchanges (PAHCE), Vina del Mar, Chile, 23-28 March 2015; pp. 1-4.

147. Gao, L.; Cheng, W.; Zhang, J.; Wang, J. EEG classification for motor imagery and resting state in BCI applications using multi-class Adaboost extreme learning machine. Rev. Sci. Instrum. 2016, 87, 85110. [CrossRef]

148. Bhagat, N.A.; Venkatakrishnan, A.; Abibullaev, B.; Artz, E.J.; Yozbatiran, N.; Blank, A.A.; French, J.; Karmonik, C.; Grossman, R.G.; O'Malley, M.K.; et al. Design and Optimization of an EEG-Based Brain Machine Interface (BMI) to an Upper-Limb Exoskeleton for Stroke Survivors. Front. Neurosci. 2016, 10, 122. [CrossRef]

149. Wolpaw, J.R.; Birbaumer, N.; McFarland, D.J.; Pfurtscheller, G.; Vaughan, T.M. Brain-computer interfaces for communication and control. Clin. Neurophysiol. 2002, 113, 767-791. [CrossRef]

150. Amiri, S.; Fazel-Rezai, R.; Asadpour, V. A Review of Hybrid Brain-Computer Interface Systems. Adv. Hum. Comput. Interact. 2013, 2013, 1-8. [CrossRef]

151. Siebert, J.; Poliński, A. Badania modelowe zastosowania pletyzmografii impedancyjnej do badania przepływu krwi w kończynach. Folia Cardiol. 1999, 6, 417-422.

152. Gradolewski, D.; Redlarski, G. Wavelet-based denoising method for real phonocardiography signal recorded by mobile devices in noisy environment. Comput. Biol. Med. 2014, 52, 119-129. [CrossRef] [PubMed]

153. Redlarski, G.; Gradolewski, D.; Palkowski, A. A System for Heart Sounds Classification. PLoS ONE 2014, 9, e112673. [CrossRef] [PubMed]

154. Jagodnik, K.M.; Thomas, P.S.; van den Bogert, A.J.; Branicky, M.S.; Kirsch, R.F. Human-Like Rewards to Train a Reinforcement Learning Controller for Planar Arm Movement. IEEE Trans. Hum. Mach. Syst. 2016, 46, 723-733. [CrossRef]

155. Celadon, N.; Došen, S.; Binder, I.; Ariano, P.; Farina, D. Proportional estimation of finger movements from high-density surface electromyography. J. NeuroEng. Rehabil. 2016, 13, 73. [CrossRef]

156. Rzyman, G.; Redlarski, G.; Krawczuk, M. Komputerowo wspomagana klasyfikacja wybranych sygnałów elektromiografii powierzchniowej. Model. Inż. 2017, 62, 81-87.

157. Subasi, A. Classification of EMG signals using combined features and soft computing techniques. Appl. Soft Comput. 2012, 12, 2188-2198. [CrossRef]

158. Mohammad, T.K.; Hasan, M.T. Comparison between kNN and SVM for EMG Signal Classification. Int. J. Recent Innov. Trends Comput. Commun. (IJRITCC) 2015, 3, 6799-6801.

159. Gokgoz, E.; Subasi, A. Comparison of decision tree algorithms for EMG signal classification using DWT. Biomed. Signal Process. Control 2015, 18, 138-144. [CrossRef]

160. Rzyman, G.; Redlarski, G.; Palkowski, A.; Tojza, P.M.; Krawczuk, M.; Siebert, J. Computing methods for fast and precise body surface area estimation of selected body parts. In Proceedings of the 2018 International Interdisciplinary PhD Workshop (IIPhDW), Swinoujście, Poland, 9-12 May 2018; pp. 316-318.

161. Li, C.; Rusák, Z.; Horváth, I.; Ji, L. Development of engagement evaluation method and learning mechanism in an engagement enhancing rehabilitation system. Eng. Appl. Artif. Intell. 2016, 51, 182-190. [CrossRef]

162. Chestek, C.A.; Gilja, V.; Blabe, C.H.; Foster, B.L.; Shenoy, K.V.; Parvizi, J.; Henderson, J.M. Hand posture classification using electrocorticography signals in the gamma band over human sensorimotor brain areas. J. Neural Eng. 2013, 10, 026002. [CrossRef] [PubMed]

163. Pazzaglia, C.; Imbimbo, I.; Tranchita, E.; Minganti, C.; Ricciardi, D.; Lo Monaco, R.; Parisi, A.; Padua, L. Comparison of virtual reality rehabilitation and conventional rehabilitation in Parkinson's disease: A randomised controlled trial. Physiotherapy 2020, 106, 36-42. [CrossRef] [PubMed]

164. Jack, D.; Boian, R.; Merians, A.; Tremaine, M.; Burdea, G.; Adamovich, S.; Recce, M.; Poizner, H. Virtual reality-enhanced stroke rehabilitation. IEEE Trans. Neural Syst. Rehabil. Eng. 2001, 9, 308-318. [CrossRef] [PubMed]

165. Sveistrup, H. Motor rehabilitation using virtual reality. J. NeuroEng. Rehabil. 2004, 1, 10. [CrossRef] [PubMed]

166. Majid, M.S.H.; Khairunizam, W.; Ikram, K.; Jing, L.M.; Sahyudi, B.N.; Zunaidi, I.; Ariffin, M.A.; Bakar, A.S.; Razlan, Z.M. Performance evaluation of a VR-based arm rehabilitation using movement sequence pattern. In Proceedings of the 2018 IEEE 14th International Colloquium on Signal Processing \& Its Applications (CSPA), Batu Feringghi, Malaysia, 9-10 March 2018; pp. 123-128. [CrossRef] 
167. Maier, M.; Rubio Ballester, B.; Duff, A.; Duarte Oller, E.; Verschure, P.F.M.J. Effect of Specific Over Nonspecific VR-Based Rehabilitation on Poststroke Motor Recovery: A Systematic Meta-analysis. Neurorehabil. Neural Repair 2019, 33, 112-129. [CrossRef] [PubMed]

168. Laver, K.E.; Lange, B.; George, S.; Deutsch, J.E.; Saposnik, G.; Crotty, M. Virtual reality for stroke rehabilitation. Cochrane Database Syst. Rev. 2017, 2017. [CrossRef] [PubMed]

(C) 2020 by the authors. Licensee MDPI, Basel, Switzerland. This article is an open access article distributed under the terms and conditions of the Creative Commons Attribution (CC BY) license (http://creativecommons.org/licenses/by/4.0/). 